\title{
Museus, mulheres e gênero: olhares sobre o passado para possibilidades do presente ${ }^{*}$
}

\author{
Bruno Brulon**
}

\section{Resumo}

$\mathrm{Na}$ Museologia, campo predominantemente constituído por mulheres no Brasil, o papel dessas profissionais se mostrou, ao longo da história da disciplina, submetido à tutela masculina, reproduzida e naturalizada nos museus. Por meio da análise histórica, este artigo busca evidenciar a subversão da dominação masculina no campo acadêmico da Museologia, por meio da mudança do papel desempenhado por museólogas brasileiras no século XX. As reflexões sobre o passado nos levam a considerar as relações de gênero na Museologia, evidenciando relações de poder construídas historicamente nesse campo, ou, ainda, nos levam a pensar uma museologia pelo viés queer, subvertendo por completo as categorias identitárias reproduzidas nos museus.

Palavras-chave: Museus, Museologia, Mulheres, Gênero, Teoria Queer.

\footnotetext{
" Recebido em 12 de outubro de 2017, aceito em 27 de fevereiro de 2018.

** Professor Adjunto do Departamento de Estudos e Processos Museológicos e do Programa de Pós-Graduação em Museologia e Patrimônio da Universidade Federal do Estado do Rio de Janeiro (UNIRIO), Rio de Janeiro, RJ, Brasil. brunobrulon@gmail.com / https://orcid.org/0000-0002-1037-8598
} 
Museums, Women and Gender: A Look at the Past to find Current Possibilities

\begin{abstract}
In museology, a field constituted predominantly by women in Brazil, the role of these professionals has been subjected to male tutelage throughout the discipline's history, and reproduced and naturalized in museums. The article uses a historic analysis to reveal the subversion of male domination in the academic field of Museology through the changing role of women museologists in the country in the $20^{\text {th }}$ century. The reflections on the past allow us to consider gender relations in museology and reveal the power relations historically constructed in this field. We also use a queer perspective to consider museology, completely subverting the identity categories reproduced in museums.
\end{abstract}

Keywords: Museums, Museology, Women, Gender, Queer theory. 


\title{
Museus, mulheres e gênero: olhares sobre o passado para possibilidades do presente
}

\begin{abstract}
Alguém pode se perguntar para que serve, afinal, "abrir-se para possibilidades", porém, provavelmente, ninguém que tenha entendido o que é viver no mundo social como o que é "impossível", ilegível, irrealizável, irreal, e ilegítimo estaria inclinado a fazer tal pergunta (Judith Butler, Gender trouble, Preface, 1999, p.viii tradução nossa). ${ }^{1}$
\end{abstract}

Diante de uma fotografia das alunas do Curso de Museus, do Museu Histórico Nacional - MHN, no Rio de Janeiro, e seus professores, datando dos anos 1940, não há equívoco sobre como estava estabelecida a relação de tutela masculina que marcava relações de gênero e poder numa época em que "o técnico em museus" não era visto como um/uma cientista ou curador, mas como um/uma assistente ou auxiliar nas funções do museu. No centro da foto (ver Figura 1), temos a imagem masculina de Gustavo Dodt Barroso ${ }^{2}$ (1888-1959), coordenador e professor do Curso, então diretor do Museu, e figura tutelar na Museologia brasileira até os nossos dias.

${ }^{1}$ No original: "One might wonder what use 'opening up possibilities' finally is, but no one who has understood what it is to live in the social world as what is 'impossible,' illegible, unrealizable, unreal, and illegitimate is likely to pose that question".

2 Escritor, político e jornalista, um dos intelectuais mais atuantes da vertente regionalista e nacionalista das primeiras décadas do século XX no Brasil. Foi diretor do Museu Histórico Nacional, primeiramente, de 1922 a 1930 e depois entre 1932 e 1959. 


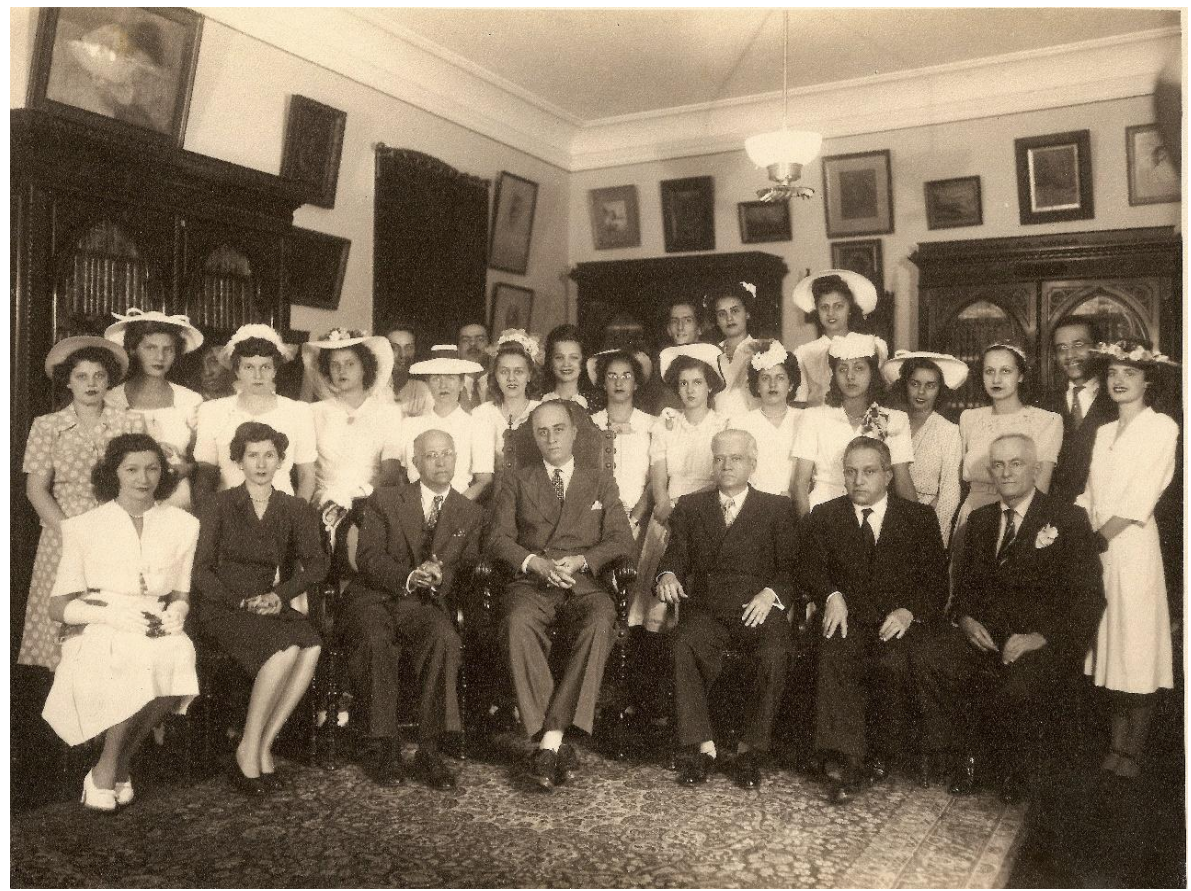

Figura 1: Formandos do Curso de Museus - Turma de 1943. Acervo do Núcleo de Memória da Museologia no Brasil (NUMMUS) da Escola de Museologia da UNIRIO, 2017.

Nas fotos tradicionais dos anos 1930 e 1940, no Curso de Museus do MHN, as alunas concluintes se colocavam em segundo plano, de pé, enquanto seus professores - em sua grande maioria homens, com algumas exceções - sentavam-se de forma imponente no centro, em primeiro plano. O que nos diz essa disposição do gênero sobre a própria constituição social da formação brasileira de "técnicos" para atuar em museus?

Como demonstra a história do campo museal, os primeiros programas para a formação de profissionais a serem criados no mundo, notadamente nas primeiras duas décadas do século $\mathrm{XX}$, não se propunham a formar diretores de museus ou administradores, mas sim "assistentes" para atuar nos museus. Por essa razão, essas primeiras escolas eram destinadas a "jovens mulheres" a serem treinadas para realizar as funções básicas de 
organização, manuseio, classificação e catalogação de objetos de museus (Cushman, 1984).

Nos Estados Unidos, por exemplo, a partir de 1910, inicia-se a formação geral para o trabalho em museus oferecida pelo Farnsworth Museum da Wellesley College. O programa seria ensinado pela bibliotecária e pesquisadora de arte Myrtilla Avery, em conjunto com a professora de arte Alice Van Vechten Brown, $e$ tinha o objetivo de formar jovens mulheres para atuar em uma variedade de funções próprias dos museus de arte (Cushman, 1984). Em 1925, o bibliotecário John Cotton Dana estabeleceu um programa de formação profissional no Newark Museum, respondendo a uma demanda pela qualificação de profissionais para atuar em museus cuja formação deveria estar, segundo ele, voltada para a educação e o serviço de público em vez de priorizar as coleções (Cushman, 1984). O curso para "aprendizes" foi divulgado por Dana exclusivamente em universidades para mulheres, de modo que por muitos anos não recebeu inscrições masculinas.

Nesse contexto, ao mesmo tempo que as mulheres eram treinadas para atuar nas funções subordinadas dos museus geralmente ligadas à organização das coleções ou à educação do público, como era o foco na escola de Dana -, ganha ênfase, em contraste, a figura do "curador", como uma competência quase naturalizada como masculina, segundo testemunha a declaração de Frederic A. Lucas, curador chefe dos Museus do Brooklyn Institute of Arts and Sciences, no início do século:

Eu acredito que o curador nasce curador, e não é feito. Não acredito que se pode treinar um homem para ser um curador. Ele é o resultado da combinação de habilidade natural e das circunstâncias (Crook, 1910:64 apud Cushman, 1984:11, tradução nossa, grifos nossos). ${ }^{3}$

${ }^{3}$ No original: "I do believe the curator is born and not made. I do not believe you can train a man to be a curator. He is the result of the combination of natural ability and circunstances". 
Tal declaração poderia representar um contrassenso, visto que os cursos de formação para profissionais de museus tinham suas vagas majoritariamente ocupadas por mulheres - dado este que não viu mudança representativa, mesmo com a introdução de uma parcela de alunos homens, tendo estes naturalmente ocupado os cargos de maior proeminência nas instituições. Todavia, recebendo a mesma formação, inicialmente pensada por muitas como um mero meio de ampliar conhecimentos domésticos, essas mulheres passavam a estar aptas a disputar esses mesmos cargos, ainda que encontrassem barreiras simbólicas que as impediam de ocupá-los.

No caso brasileiro, podemos observar que o campo museal serviu a algumas mulheres como instrumento para subverter a diferença natural, radical, irredutível e universal (Chartier, 1995) que lhes era imposta, desbravando, elas mesmas, um campo de atuação profissional que se mostrou, em seus primeiros anos e até o presente, povoado predominantemente por museólogas.

Assim, compreendendo a submissão imposta como uma forma de violência simbólica, este trabalho pretende explorar a relação de dominação, como uma relação histórica, cultural $e$ linguisticamente construída, buscando responder como ela se traduziu no campo museal no Brasil, e como ela pôde ser subvertida no processo de constituição do campo da Museologia, apontando para suas consequências, materiais e simbólicas, nas instituições do presente.

\section{O que está implicado, historicamente, na categoria "mulher" ou "mulheres"?}

Nas ciências humanas, a História é uma das disciplinas que mais tardiamente apropriou-se das categorias "mulher" ou "mulheres" como categorias analíticas de pesquisa. Segundo as autoras Rachel Soihet e Joana M. Pedro (2007), grande parte desse retardo se deveu ao caráter universal atribuído ao sujeito da história, representado pela categoria "homem". Na historiografia dita tradicional acreditava-se que, ao falar dos homens, as 
mulheres estariam sendo igualmente contempladas, o que não correspondia à realidade. Por outro lado, também não eram todos os homens que estavam representados nesse termo que, em geral, se referia de modo hegemônico ao homem branco ocidental $e$ heterossexual. De acordo com a historiadora Joan Scott (1992), as tentativas de incorporação das mulheres no sujeito universal da História trouxeram à tona uma situação repleta de ambiguidades, em parte já resolvidas entre as historiadoras e historiadores que se voltaram para esse tema nas últimas décadas.

No campo de estudos que se convencionou chamar de "História das mulheres e das relações de gênero", a categoria "mulher" foi e ainda vem sendo objeto de disputas acirradas (Soihet; Pedro, 2007). Esse ramo de estudos é fundado, de forma marcante, nos anos 1970, a partir da constatação da negação ou do esquecimento das mulheres na história, que é endossada pelo feminismo e sua articulação com o desenvolvimento da Antropologia e da História das Mentalidades, além dos estudos em História Social. Nesse primeiro estágio de efervescência intelectual, dois objetivos da reflexão se estruturam: o de tornar as mulheres aparentes dentro de uma história pouco preocupada com a diferenciação sexual, e o de denunciar a opressão, a exploração e a dominação (Perrot et alii, 1986). Nesse contexto particular, a ideologia e a denunciação são constitutivas do objeto estudado, e configuram a principal característica dos trabalhos desenvolvidos.

A partir dos anos 1980, esse novo campo de pesquisas históricas se organiza, afinando os seus conceitos e aportando um olhar crítico sobre o que se estava produzindo. Para Perrot et alii (1986), essa produção era marcada por algumas fraquezas, resumidas pelas autoras, entre as quais: a limitação de temáticas ligadas a uma suposta "natureza" feminina; a frequente utilização da dialética da dominação; a inflação de estudos sobre os discursos normativos que deixam de levar em conta as práticas sociais e os modos de resistência a esses discursos; uma falta de reflexão metodológica e sobretudo teórica. Cada vez mais, as ambiguidades presentes na categoria "mulher" se tornariam evidentes nesses primeiros estudos que se tornavam mais críticos 
na medida em que questionavam a homogeneidade dessa categoria nas narrativas da História.

É nessa década de 1980 que a introdução da ideia de gênero ${ }^{4}$ rompe com a ênfase política das análises e todo um ramo de estudos específico conquista o seu espaço. Parte desses estudos entende o gênero como um termo aparentemente neutro, desprovido de propósito ideológico imediato. A história das mulheres como um campo de estudos específico, segundo aponta Joan Scott (1992), iria emergir, nessa perspectiva, como uma evolução do feminismo e, em seguida, uma evolução para o gênero, isto é, da política para a história e para a análise historiográfica. Tal démarche, em alguns casos é percebida de maneira positiva, como um retorno à história, enquanto outras interpretações negativas encaram essa transformação como um processo de "despolitização". 5

Essas primeiras tensões levaram a se questionar a viabilidade da categoria introduzindo-se a "diferença" como um problema a ser analisado (Soihet; Pedro, 2007). Na perspectiva restritiva em que se pautavam muitos dos trabalhos, colocando em primeiro plano dos interesses da pesquisa a dialética da dominação e da opressão, ignoravam-se as variações frequentes e complexas dos jogos de poder estabelecidos, bem como a existência de poderes exclusivamente femininos. Para Perrot et alii (1986), não deveria ser tarefa da história das mulheres a de reconstituir os seus discursos e saberes específicos, nem de atribuir a elas poderes esquecidos, mas a de compreender como uma "cultura feminina" se construiu no interior de um sistema de relações desiguais.

Neste trabalho, nos propomos a olhar para as categorias "mulheres", e, mais precisamente, "museólogas", buscando

4 Gênero, nesse contexto, entendido como a divisão "natural" dos sexos. Cf. Scott (1995).

5 Muitos daqueles que escrevem a história das mulheres consideram-se envolvidos em um esforço altamente político para desafiar "a autoridade dominante na profissão e na universidade, visando mudar a maneira como a história é escrita" (Scott, 1992:67). 
compreender como, no interior de uma hierarquia de poder estabelecida em que as mulheres não ocupavam as posições profissionais mais proeminentes, se estabeleceu um campo profissional acadêmico graças à atuação de museólogas, deixando os museus como lugar de atuação técnica e tornando-os objeto de estudos de uma disciplina acadêmica nascente.

\section{Qual era a representação hegemônica do "museu" herdada dos séculos XVIII e XIX?}

Qual era o museu do início do século XX, em que iriam atuar como profissionais um número majoritário de mulheres? Quais eram as relações de poder que permeavam essa instituição disseminada a partir da Modernidade na Europa.

No momento em que são criados, esses museus modernos, instituições fundadas a partir do processo de reapropriação do patrimônio nacional na insurreição que se deu no bojo da Revolução Francesa contra os símbolos da monarquia finda ${ }^{6}$, fazem acessíveis ao público os bens da Nação. Até o fim do século XVIII, o público dos museus se resumia essencialmente aos conhecedores, aos sábios, amadores e artistas, aos quais a maior parte dos estabelecimentos, fossem privados ou públicos, abriam as suas portas. A entrada no museu, até esse período, era considerada um privilégio (Mairesse, 2005), e um privilégio majoritariamente masculino.

\footnotetext{
6 A insurreição de 10 de agosto de 1792 coloca um fim à monarquia e simbolicamente são derrubadas as estátuas dos reis nas praças públicas. $\mathrm{O}$ poder dado ao povo incita a destruição dos símbolos do Antigo Regime, que ofuscavam a imagem de população livre e legitimavam um iconoclasmo oficial. "Cívicas e patrióticas", as depredações da Revolução não eram meramente vândalas. Representavam o repúdio a um conjunto de bens, "emblemas de uma ordem finda". O museu se instaura aqui, como um abrigo das obras que, em parte, precisavam ser resguardadas do vandalismo, e, de outra forma, constituíam o patrimônio nacional francês (Choay, 2001).
} 
Eram os homens também, aqueles que tinham o dinheiro $e$ a influência para constituir coleções particulares. ${ }^{7}$ Os estudos mais conhecidos sobre os gabinetes de curiosidade, antecedentes do museu moderno, documentam que essas coleções estavam associadas às figuras de homens poderosos que podiam acessar àqueles objetos considerados como "maravilhas" (Levin, 2010). A natureza privada desses empreendimentos era uma característica fundamental para o prestígio desses senhores. Nos primeiros museus públicos do século XIX, também ligados ao nome de grandes doadores e benfeitores, era comum que se designassem horários especiais para a visita da classe trabalhadora e das mulheres de classe alta, separadamente da visita dos homens cultos da elite.

A revolução que tem início com a abertura dos museus para as sociedades ocidentais é, logo, uma revolução conceitual, sustentada fortemente pelos Estados nacionais. Um processo de realocação de valores (e de objetos) é colocado em prática quando a missão que antes era conferida aos príncipes e à Igreja, de produzir uma continuidade com o passado gerando prestígio, passa a ser atribuição da Nação. Nesse projeto, não havia lugar ou privilégio para as mulheres. Ainda que constituíssem parte do "público" e da "sociedade", eram raramente pensadas como cidadãs, e apareciam no discurso dessas instituições, diluídas nas narrativas hegemônicas que priorizavam o sujeito universal.

A Revolução Francesa, cujo mérito, como lembra Soihet (1997), se deveu a sua contribuição ao reconhecimento dos direitos humanos, representou contraditoriamente para as mulheres um retrocesso em diversos níveis. Como aponta a autora, apesar do papel relevante que desempenharam no movimento, quando da institucionalização da nova ordem, viramse excluídas da cidadania política e civil. E a justificativa para a manutenção de barreiras sociais e culturais era, ainda, a da natureza diferenciada dos dois sexos.

7 Sobre a constituição das coleções modernas e os homens que as constituíram, ver por exemplo Pomian (1984). 
Afinal, homens e mulheres apresentavam uma fisiologia diferente, o que lhes impunha papéis sociais diversos. [...] Para as mulheres, reservava-se uma cidadania específica a ser exercida no recesso do lar, como mãe de futuros republicanos, cabendo-lhe a defesa dos interesses familiares (Soihet, 1997:11).

Ao longo de todo o século XIX em que os museus nacionais se desenvolveram na Europa, o tema da civilização, simultaneamente nacional e ligado à lembrança da Revolução Francesa, como observa Starobinski (2001), esteve atrelado a essas instituições e a sua função educativa. Como demonstrou Norbert Elias (1994), a ideia de "civilização" representava algo efetivamente útil; ela busca enfatizar o que é comum a todos os seres humanos ou às nações ou que "deveria sê-lo", sistematizando, assim, a supressão das diferenças. Os processos de formação identitária, nesse sentido, estavam mais preocupados em produzir nações homogêneas, do que se voltar para suas diferenças internas - fossem elas de identidade de gênero, étnica ou de classe social.

Foi, notadamente, em represália à trindade nacionalidade, masculinidade e colonialismo enaltecida em "templos" como o Louvre, em Paris, ou a National Gallery de Londres, que, entre 1913 e 1914, mulheres que faziam parte do movimento sufragista na Europa atacaram diversos museus, destruindo obras que reproduziam a imagem idealizada da mulher para as novas gerações do século que se iniciava. A destruição de pinturas em um dos museus mais influentes do mundo ocidental, como a National Gallery, não foi arbitrária. Segundo relata Amy K. Levin (2010), o governo de Winston Churchill na Inglaterra prendeu as sufragistas por destruição do patrimônio público, abalando o status quo. Ao reclamarem o lugar pela exposição de representações da feminilidade, essas mulheres reivindicavam publicamente a representação de si mesmas, "desafiando os pilares ideológicos e econômicos da autoridade cultural" (Levin, 2010:3). Esses movimentos foram semelhantes ao que se repetiu 
mais tarde em Nova Iorque, liderado pelo grupo Guerrilla Girls, ao desafiar a autoridade do Modern Art Museum - MOMA e chamar a atenção para a ausência de representações de artistas mulheres em museus como o Metropolitan Museum of Art, no final dos anos 1980.

O século XX foi marcado pela ênfase na ideia dos museus como instrumentos pedagógicos, disseminando-os como uma instituição social. Soma-se a essa nova tendência, uma necessidade crescente por profissionais qualificados para atuarem nos museus, capazes de mediar essa relação pedagógica com os diferentes públicos.

No momento em que começam a se multiplicar no mundo os primeiros cursos de formação para profissionais de museus, as mulheres se tornam rapidamente a sua principal clientela, fosse pelo tipo de qualificação pouco específica, fosse pelo desinteresse dos homens por esses cargos técnicos, ou, ainda, pela vocação pedagógica atribuída a elas e à natureza feminina imaginada desde o Iluminismo. Não se pode ignorar que foi no pós-guerra, quando o Conselho Internacional de Museus - ICOM e a UNESCO ${ }^{9}$ são criados recomendando mundialmente a abertura sistemática de novos museus, que começaram a ser criados novos cursos para a formação de profissionais especializados para atuar nessas instituições. Esse é o momento em que, tendo perdido seus maridos para a guerra, muitas mulheres buscam o seu lugar no mercado profissional em ascensão. $\mathrm{O}$ trabalho em museus não se mostrava, para muitas delas, como uma vocação impensada.

Como demonstra Soihet (1997), desde a segunda metade do século XIX, as mulheres eram caracterizadas, segundo a lógica dos filósofos iluministas, como o ser da paixão, da imaginação, excluídas da genialidade mesmo mediante o acesso à literatura e à

\footnotetext{
8 Grupo de artistas feministas e ativistas dos Estados Unidos, identificadas por usarem máscaras de gorilas, que em suas manifestações expõem as relações de gênero e étnicas nos museus e no mundo da arte.

9 Ambos os órgãos criados em 1946.
} 
formação em determinadas ciências. Tendo como fato incontestável a "inferioridade da razão",

Relacionando-se, apenas, com o mundo ao nível do concreto, mantinham-se perpetuamente na infância, incapazes de ultrapassar o mundo da domesticidade que lhes fora legado pela natureza (Soihet, 1997:9).

Tais pressupostos ganham força durante o século XIX, adquirindo respaldo científico quando a medicina social assegura constituírem-se como características femininas, por razões biológicas, "a fragilidade, o recato, o predomínio das faculdades afetivas sobre as intelectuais, a subordinação da sexualidade à vocação maternal" (Soihet, 1997:7), etc. O ponto central, para Soihet, é que tais teorias construídas e instauradas por homens que estabelecem um duplo discurso, do homem sobre o homem $e$ do homem sobre a mulher, ao restringirem a liberdade $e$ a autonomia femininas, convertendo uma relação de diferença numa hierarquia, configuram uma forma de violência simbólica.

Quando o Curso de Museus é criado em 1932, sob os auspícios do MHN, na cidade do Rio de Janeiro, durante a gestão de Rodolfo Augusto de Amorim Garcia ${ }^{10}$ (1873-1949), e posteriormente gerido por Gustavo Barroso, a principal demanda à qual esse curso, sem precedentes no país, respondia era à necessidade por profissionais para atuarem no próprio museu, demanda esta apontada desde a sua criação, em 1922. A profissão de museólogo, ou mesmo o cargo de conservador, eram inexistentes. Logo, o curso de perfil essencialmente técnico seria criado em 1932 com a finalidade de aproveitar os seus egressos na carreira de oficial, criada no regulamento do museu ainda nos anos $1920 .{ }^{11}$ Esses cargos, ainda que criados na estrutura de um

\footnotetext{
${ }^{10}$ Advogado, escritor, linguista e historiador, Garcia foi diretor do Museu Histórico Nacional entre dezembro de 1930 e novembro de 1932, quando assumiu a direção da Biblioteca Nacional.

${ }^{11}$ Segundo o regulamento, foram criados no Museu Histórico os cargos de diretor, chefe de seção, $1^{\circ}$ oficial, $2^{\circ}$ oficial, $3^{\circ}$ oficial, datilógrafo, porteiro,
} 
museu com perfil militar, correspondiam às funções, por exemplo, de manter "em boas condições de segurança, ordem $e$ conservação os objetos que constituíam as coleções, assim como o mobiliário existente nas seções", ou de "catalogar e fazer catalogar tais objetos, procurando trazer os catálogos em dia e enriquecê-los de notas elucidativas", além de encarregar-se, eventualmente, "do ensino das matérias do curso técnico que devem ser lecionadas no Museu" (Brasil, 1923).

Tais funções, pensadas a princípio como meramente técnicas, de conservação, organização e ensino, seriam interpretadas socialmente como funções em grande parte femininas, e com essa finalidade o Curso de Museus atrairia um número majoritário de alunas, algumas delas posteriormente se tornando professoras das mesmas disciplinas técnicas que constituíam as matérias cursadas. A única disciplina com conteúdos especificamente teóricos ligados ao estudo dos museus, intitulada "Técnica de Museus", seria implementada em 1933, e ministrada pelo próprio Gustavo Barroso ao longo dos anos 1930 e 1940.

Diferentemente de alguns dos cursos criados no mesmo contexto sócio-histórico na América do Norte ou na Europa, o Curso de Museus do Rio de Janeiro não se definia explicitamente como um curso para mulheres de uma certa classe social, como um curso complementar para a formação em cultura geral. No entanto, sua estrutura disciplinar $e$ as hierarquias estabelecidas na própria organização do museu deixam evidentes a figura tutelar masculina $e$ o lugar relegado às alunas, e técnicas do museu, num momento em que a cultura da elite devia ser aprendida para as mulheres de modo a poder ser reproduzida na educação dos filhos. A priori subordinadas à tutela masculina no campo profissional dos museus, as mulheres brasileiras seriam responsáveis por subverter as relações de gênero ao passarem, não de forma facilitada ou natural, a ocupar os principais cargos

ajudante de porteiro, guarda, servente e secretário, que seria um $2^{\circ}$ oficial com gratificação (Brasil, 1923). 
disponíveis, deixando de serem vistas como "assistentes" ou "donas" 12 para se tornarem "doutoras" e "museólogas".

Como a dominação simbólica pôde ser manipulada, afastada e, finalmente, subvertida?

Reconhecer a dominação masculina na sociedade e nos museus na primeira metade do século $\mathrm{XX}$, não nos impede de reconhecer também a existência de variações e manipulações por parte daquelas dominadas, que foram preponderantes para a transformação do campo da Museologia no Brasil. Nas palavras de Soihet,

[...] a aceitação, pela maioria das mulheres, de determinados cânones não significa, apenas, vergarem-se a uma submissão alienante, mas, igualmente, construir um recurso que lhes permitam deslocar ou subverter a relação de dominação (Soihet, 1997:12).

Nesse sentido, identificar e definir os poderes femininos permitidos por uma situação de sujeição $e$ de inferioridade significa entendê-los como uma reapropriação e um desvio dos instrumentos simbólicos que instituem a dominação masculina, contra o seu próprio dominador. Para Chartier (1995), trata-se de uma "tática" que mobiliza para seus próprios fins a representação imposta, de modo que esta última é aceita, porém desviada contra a ordem que a produziu. Tal movimento de apropriação e desvio da norma dominante para, finalmente, transformá-la pode ser visto como marcante do processo de constituição do campo acadêmico da Museologia, no qual as mulheres ocupam as principais posições de poder, construído a partir de sua atuação ou sujeição inicial à hierarquia imposta pelos homens nos museus.

Com as primeiras turmas já formadas pelo Curso de Museus, qualificando homens e mulheres para atuarem como

${ }^{12}$ Como eram comumente chamadas as professoras do Curso de Museus, até os anos 1970 . 
técnico(a)s, a entrada de uma mulher por meio de concurso público para atuar como funcionária de uma dessas instituições era, ainda, um feito raro e questionado como ato feminista em si $e$ demasiadamente transgressor ${ }^{13}$. Em 1939, o Departamento Administrativo de Serviço Público (DASP) realiza o primeiro concurso para Conservador de Museus, classificando as ex-alunas do Curso do Museu Histórico Nacional, Elza Peixoto Ramos, Lygia Martins Costa, Maria Barreto, Nair de Moraes Carvalho, Octávia Corrêa de Oliveira, Regina Liberalli, Regina Real e Yolanda Portugal, além dos ex-alunos Adolpho Dumans e Luiz Marques Poliano. É então implantada, no país, a carreira de Conservador de Museus, vinculada ao Ministério da Educação e Saúde, ocupada, desde aquele momento, majoritariamente por conservadoras.

A partir dos anos 1940, algumas das alunas das primeiras turmas do curso começam a publicar textos ligados a questões do recém-legitimado campo dos museus, da museografia ou técnicas em museus. Entre elas, destacaram-se as obras de Regina Real e Regina Liberalli. Ainda na primeira metade do século, num contexto em que, para mulheres, diplomar-se em curso superior poderia ter caráter transgressor, mesmo para as filhas das elites brasileiras (Lopes, 2008), o Curso de Museus começa a ser visto como um destino menos feminista para mulheres que desejassem obter uma formação. Esse caráter se justifica, principalmente, pelo fato de o curso se destinar à formação de técnicas ou assistentes para atuarem nas funções secundárias dos museus, como já mencionado anteriormente. A presença de mulheres matriculadas no curso, expressiva desde o seu início, se torna predominante nos anos 1940, de modo que de uma diferença de 9 homens para 4 mulheres matriculadas em 1937, em 1941, a diferença passa a ser de 15 homens para 63 mulheres matriculadas.

\footnotetext{
${ }^{13}$ Maria Margaret Lopes, por exemplo, irá se referir às críticas irônicas direcionadas à Bertha Lutz, por Lima Barreto, ao prestar o primeiro concurso público de ingresso para o Museu Nacional ainda nos anos 1920 (Lopes, 2008).
} 
Nas décadas de 1940 e 1950, os formandos das primeiras turmas começam a assumir a docência do curso, substituindo os seus antigos professores. Entre os nomes de ex-alunas que ocuparam cargos na docência nesse período destacam-se Nair de Moraes Carvalho (Escultura), Yolanda Marcondes Portugal (Numismática), e Octavia de Castro Corrêa (Técnica de Museus), esta última ocupando a disciplina ministrada anteriormente por Barroso.

A partir da reforma curricular de 1944, o curso começava a ser estruturado para a sua futura entrada na universidade, tendo a sua duração ampliada de dois para três anos e uma seleção por meio de vestibular (Sá, 2007). Com a criação do cargo de coordenador, diretamente subordinado ao diretor do MHN, o curso passa a ter uma administração própria. A professora Nair de Moraes Carvalho (1914-2018) ${ }^{14}$ torna-se a primeira coordenadora, função que manteria por 23 anos, até 1967.

Desde final dos anos 1960 até início de 1970, o processo de mudança na afiliação do curso, que progressivamente deixaria o museu para se ligar a uma universidade, é marcado pelo processo concomitante de uma mudança terminológica chave, passando a se chamar oficialmente Curso de Museologia. Com essa mudança estatutária e jurídica tem-se o primeiro indício da formação de um campo acadêmico ao qual o termo "Museologia" faria referência.

A década de 1970, quando renasce, em uma universidade, o Curso de Museologia, as professoras que antes lecionavam disciplinas ligadas ao universo técnico dos museus e a suas coleções, dão início à luta por sua legitimação dentro da estrutura acadêmica a que agora se integrava. De "técnicas de museus" a professoras universitárias em um curso superior, essas mulheres seriam levadas a repensar a própria profissão e sua atuação, que

\footnotetext{
${ }^{14}$ Museóloga, formada pelo Curso de Museus do Rio de Janeiro, na turma de 1936. É aprovada no primeiro concurso para Conservador de Museus, em 1939, e passa a lecionar no Curso em seguida. Tendo sido ensinada por uma geração de professores quase que exclusivamente homens, em 1944, torna-se coordenadora do Curso de Museus, a primeira mulher a ocupar um cargo de direção na estrutura do Museu.
} 
deveria percorrer caminhos ligados à academia em um novo campo de saber a ser desbravado.

É a partir dessa década que começam a aparecer, no contexto nacional bem como nos principais fóruns internacionais de debates em torno da estruturação disciplinar para o campo, os nomes de museólogas brasileiras cujas contribuições acadêmicas seriam reconhecidas, no Brasil e no exterior. Podemos citar, entre diversas outras, os nomes de Fernanda de Camargo Moro (RJ), Waldisa Rússio Guarnieri (SP), Tereza C. Moletta Scheiner (RJ), Maria de Lourdes Parreiras Horta (RJ), Maria Cristina Oliveira Bruno (SP), Marília Xavier Cury (SP), Maria Célia Teixeira Moura Santos (BA), Heloisa Helena Costa (BA).

Nos anos 1980 e 1990, quando as primeiras publicações internacionais em Museologia começam a circular, o número expressivo de brasileiras entre os autores $e$ autoras referenciais para o campo já não pode ser ignorado. No periódico anual do Comitê Internacional de Museologia - ICOFOM, o ICOFOM Study Series - ISS, publicado desde 1983, apesar de os autores serem em sua maioria global homens, entre os brasileiros, as museólogas estariam em maior número, publicando textos teóricos que iriam fundamentar o campo da Museologia em âmbito mundial. Nessa publicação, o principal fórum de debates acadêmicos na área no período referido, a produção feminina brasileira seria expressiva. Na década de 1980, no total dos artigos assinados por brasileiros, encontramos 22 trabalhos assinados por autoras, em contraposição aos 3 trabalhos assinados por autores que produziram textos em Museologia. Nos anos 1990, a diferença passa a ser de 38 trabalhos de autoras para apenas 9 trabalhos de autores da Museologia brasileira nessa publicação.

O crescimento acadêmico da Museologia no Brasil viria com a realização do doutoramento da maioria dos professores dos cursos do Rio de Janeiro e da Bahia que se concretizaria, em grande parte, até a primeira década do século XXI. Com a ausência do mestrado e do doutorado em Museologia até meados dessa década, essas professoras tiveram que optar pela formação em áreas afins, permeando os conteúdos museológicos com 
métodos e conceitos da História, das Ciências Sociais, da Ciência da Informação, da Educação, da Sociologia, da Antropologia e da Comunicação, $e$ finalmente estabelecendo os primeiros programas de mestrado (2006) e doutorado (2011) do país.

É flagrante, na investigação do papel dessas museólogas, a atuação que tiveram nos interstícios de um sistema de dominação instaurado, para, a partir de suas trajetórias nos museus, encontrando a brecha para sua emancipação acadêmica, engendrarem o campo acadêmico da Museologia, como um campo em que as relações de gênero estruturantes da sociedade brasileira começavam a ser subvertidas.

\section{Por que discutir gênero na Museologia?}

Em 1943, no Curso de Museus, Fortunée Levy, conservadora do museu, ensinava na disciplina de Armaria, que os armeiros europeus "também cogitaram de fabricar armas especiais para as mulheres" (Levy, 1943:499). Segundo essa professora, cujo artigo publicado nos Anais do Museu Histórico Nacional, no mesmo ano, foi o primeiro a tratar da diferença de gênero inscrita em objetos da coleção do museu, as armas feitas para mulheres "são pequenas, de acabamento caprichado, lembrando melhor joias que objetos mortíferos". Buscando explicar a existência desses objetos na coleção do MHN, Levy (1943:507) afirmava que "é preciso considerar esse particular feminino que lhe é nato; a mulher não é de temperamento guerreiro, ela só entra em luta para a defesa, seja qual for a origem desta".

Pouco a pouco, no campo dos museus no Brasil, as diferenças de gênero se tornariam cada vez mais evidentes, fosse nas coleções dos museus tradicionais - e aqui nos referimos a um museu com acervo militar e gerido por homens cultos - fosse nas relações profissionais que estabeleciam certas hierarquias - o que se traduz no fato de o Curso de Museus passar a ter como coordenadora a professora Nair de Moraes Carvalho, em 1944, enquanto o museu continuava a ser dirigido por Gustavo Barroso 
nos anos que se seguiram. Contudo, seria necessário um olhar outro, distanciado dos museus e, ao mesmo tempo, um ponto de vista subalterno às suas representações hegemônicas para que a Museologia começasse a reconhecer as relações de gênero na estruturação desse campo do saber.

Não se pode ignorar, entretanto, a enorme lacuna de pesquisas que resultem em produções reflexivas discutindo gênero e sexualidade que ainda se faz marcante na Museologia atual, se mantendo, esta disciplina, muito aquém de outras ciências humanas e sociais que já vêm há algumas décadas travando debates críticos e evidenciando seus centros políticos $e$ normativos.

Como resultado do aumento significativo do número de mulheres atuando em museus ao longo do século XX - já referido na seção anterior - a profissão se modifica de um domínio masculino privilegiado para um campo em que o papel educativo e social dos museus passa a ser progressivamente associado às mulheres. Contudo, apesar de se configurar como um campo formado majoritariamente por mulheres $e$ homossexuais masculinos - além de lésbicas e bissexuais (Levin, 2010) - , o campo museal continuou a reproduzir narrativas marcadas pela ausência da representação das mulheres e pelas distorções das identidades gays, lésbicas, bissexuais e transgêneros na história como contada pelos museus.

Os museus, ao longo de sua existência moderna, serviram de palco para encenar os cânones de identidades masculinas centradas na matriz cultural europeia e, logo, imperial. É no bojo do processo violento da colonização na Europa que os primeiros museus, templos das heranças dos príncipes do além-mar, chegam às colônias com a missão de normatizar as relações existentes, incluindo as relações de gênero, e moldando os comportamentos por meio do controle dos imaginários. Não por acaso, carregando ainda no presente a herança das relações de poder construídas no passado, os museus hoje se veem, em parte, a serviço daquelas identidades que temem as experiências culturais diversas, 
percebendo as diferenças como ameaça ao patriarcalismo e à heteronormatividade que ainda vigoram.

\section{Que mulheres na Museologia e nos museus? Uma categoria em disputa}

Apesar de a Museologia no Brasil se configurar como um campo majoritariamente feminino, até o presente constatamos a ausência de narrativas nos museus e de estudos reflexivos na academia que assumam o gênero como questão estruturante. Tal paradoxo se dá muito mais por fatores simbólicos do que numéricos, como vêm mostrando, em diversas áreas, as teorias feministas que ainda não marcaram presença expressiva no seio da Museologia e dos museus.

Para além de propor uma Museologia feminina, esses olhares e teorias que começam a permear o campo museológico em estudos como a coletânea em língua inglesa organizada por Amy K. Levin (2010) ou os já desenvolvidos em língua portuguesa por autoras como Aida Rechena (2012) e Ana Audebert (2016) abrem uma via de reflexão mais ampla para pensar o lugar da diferença nos estudos e teorias museológicos, assim como nas práticas museais.

De forma expressiva, os estudos de gênero $e$ as teorias feministas influenciam os estudos de museus (museum studies) apenas a partir de meados dos anos 1980, em pesquisas cujo foco estava no papel das mulheres como atrizes no campo dos museus e do patrimônio (Bounia, 2012). Desde então, diversos autores chamaram a atenção para o fato de que os museus são espaços onde as demarcações de gênero são flagrantes e onde a produção feminina e a história das mulheres são desapreciadas ou mal representadas nas narrativas em que predominam as noções estereotipadas de masculinidade e feminilidade.

Evidenciando o padrão normativo das narrativas nos museus, a história de gênero, um campo longe de ser homogêneo, constituiu desde as últimas décadas do século $\mathrm{XX}$, uma crítica a partir das abordagens desconstrutivistas à História tradicional. Por meio dessa desconstrução, a História se tornou um campo 
altamente subjetivo, se abrindo para perspectivas que questionam $e$ revisam o sujeito hegemônico constituído no bojo das percepções positivistas do passado (Hantzaroula, 2011 apud Bounia, 2012). Como consequência, as representações de gênero em exposições museológicas assim como a igualdade nas oportunidades de emprego (sobretudo nos cargos de direção que, no contexto mundial ${ }^{15}$, ainda pertencem, em sua grande maioria, aos homens) passam a ser discutidas dentro do debate mais amplo sobre inclusão social nos museus.

A produção das últimas décadas, sobretudo a que relaciona os estudos de gênero aos estudos de museus, bem como os debates travados em disciplinas afins como a História e a Antropologia, já não pode ser ignorada por uma Museologia que se pensa pós-moderna, mas que se perpetua, no presente assim como no seu passado tradicional, como um campo normativo em que as categorias de gênero estão dadas sendo as definições hegemônicas naturalizadas nos discursos das instituições. Uma museologia que pensa o gênero, reflexiva e descolonizada, ainda está em vias de se fundamentar, sem encontrar de forma sistemática e consciente os seus referenciais e a metodologia para realizar a ruptura necessária com a epistemologia dominante.

Pensar a história das mulheres na Museologia nos leva inevitavelmente a perguntar, como fez antes de nós a historiadora Joan Scott (1992:77), "que outros pontos de vista foram excluídos ou suprimidos?".

A partir da introdução da categoria "gênero" como uma categoria indispensável para pensar a Museologia nos séculos XX $e$ $\mathrm{XXI}$, para além de nos confrontarmos com a questão da diferença entre os sexos, somos convidados a levantar a questão das diferenças dentro da diferença (Scott, 1992). Tal questão contribui para abalar a oposição fixa entre homens e mulheres e suscita a

\footnotetext{
${ }^{15}$ Segundo os dados apresentados por Marjorie Schwarzer sobre o contexto dos Estados Unidos, os homens ocupam 53 porcento das posições de diretores em museus de pequeno ou médio porte, e 75 porcento das posições de diretores das instituições maiores e com mais recursos no país (Schwarzer, 2010).
} 
reflexão crítica sobre as próprias categorias do "homem" e da "mulher" como insuficientes para dar conta dos sujeitos $e$ narrativas representados no campo.

A partir da problematização da própria categoria heterogênea "mulheres", somos levados a reconhecer, no momento da estruturação da Museologia no século XX, um campo formado por mulheres brancas e heterossexuais. Onde estão, por exemplo, as mulheres negras nos retratos que constroem a memória da Museologia no Brasil? Quem está se perguntando sobre sua ausência nas primeiras décadas de existência dessa disciplina branca? Os estudos relativamente recentes que introduzem a noção de interseccionalidade (Crenshaw, 1991) para pensar as diferenças contidas nessas categorias não homogêneas nos levam a questionar onde estão na história da Museologia as mulheres negras, as lésbicas, as transgêneros não representadas no discurso museal hegemônico, e tampouco nos estudos museológicos de gênero.

\section{Da museologia "de gênero" a uma museologia sob o viés queer}

Com narrativas marcadas pela ausência deliberada das experiências gays, lésbicas, bissexuais e transgêneros na história, apesar do que se vê nos seus quadros de funcionários, os museus do século $\mathrm{XX}, e$, em sua maior parte, aqueles do século XXI, refletem o sexismo e a estrutura patriarcal que os fundou no bojo do colonialismo europeu.

O papel desempenhado pelas mulheres e por sujeitos LGBTQ no que se refere aos museus do presente se ve drasticamente limitado nos regimes de valor que restringem a expressão livre de suas identidades, ou mesmo o espectro variante que indica a não identidade como caminho para subverter a norma. Como aponta Levin (2010), em muitos lugares, as histórias de gays e lésbicas podem ser documentadas mais comumente em memoriais (em que são representados no passado encerrado) do que nos museus (onde seriam representados no presente vivo), 
por meio dos traços de sua ausência, como no caso dos triângulos cor de rosa nos museus do Holocausto.

Com efeito, pensar nas memórias invisíveis de sujeitos apagados da história, uma vez evanescidos das sociedades em que viveram, pode apresentar desafios inéditos aos museus do século XXI: por exemplo, como representar as histórias de homossexuais e transgêneros visto que a maior parte dos seus pertences não diferem daqueles de qualquer outro indivíduo, heterossexual, homossexual ou queer?

Percebidos como dispositivos que atuam sobre as subjetividades, os museus tradicionalmente operam no sentido de manter as minorias (a classe trabalhadora, as mulheres, os negros, os indígenas, os homossexuais, os transgêneros...) dentro das normas sem perturbar a ordem estabelecida e os comportamentos aprovados social e culturalmente por uma elite masculina, branca $e$ heterossexual. Essas minorias, relegadas às margens dos museus $e$ das sociedades onde suas memórias (re-)existem e são transmitidas por vias subterrâneas, por vezes subvertem as estruturas convencionais de significação reconstruindo as performances culturais que representam sua identidade a partir de suas próprias interpretações nas exposições dos museus.

Um museu queer é aquele que, ao invés de trazer a margem para o centro ou de se configurar como um museu das margens, transpõe as fronteiras entre as margens e o centro, promovendo um novo entendimento das relações de poder e colocando em questão a sua própria função como dispositivo social que serve a certos sujeitos da história. Sua função é transgredir para transformar o social subvertendo as normas que emprisionam as identidades por meio de uma outra lógica cultural.

Nesse sentido, é importante distinguir as abordagens LGBTQ e a aplicação da teoria queer ou dos estudos queer aos museus. Enquanto os museus que enfocam especificamente a causa LGBTQ estão preocupados com questões de visibilidade, a teoria queer apresenta um enfoque mais explícito no gênero como uma construção social (Levin, 2010). A noção de queer, ainda pouco clara na Museologia e nos museus, abarca as possibilidades de 
uma sexualidade que se percebe mais aberta e que escapa àquilo que é determinado como norma. O termo pode incluir as identidades gays, lésbicas e bissexuais, mas se abre a diversas outras possibilidades de existir e de se representar culturalmente no mundo, incluindo os transgêneros e os intersex.

Se, na maior parte dos museus do mundo, não é comum encontrarmos narrativas que tratem dos homossexuais $e$ bissexuais, ainda mais raro são as narrativas que transcendem as categorias de gênero aceitas para discutir, por exemplo, a identidade transgênero ou dos indivíduos intersex. Os museus do sexo, por exemplo, atuam como museus queer na medida em que apresentam o gênero de uma maneira livre das divisões binárias de sexo e da estrutura dominante que não desassocia gênero, sexo e desejo.

No entanto, se faz necessário esclarecer que o atributo "queer" se revela distinto por sua relação referencial ao gênero e à sexualidade. Pensar um "museu queer" significa, ao mesmo tempo, evidenciar e romper com a história dessa instituição que foi cúmplice da construção da heteronormatividade. A história do sujeito hegemônico representado até os nossos dias na grande maioria dos museus está estreitamente ligada à violenta história do colonialismo iniciada na Europa e do imperialismo como uma tentativa desigual de se dominar os imaginários culturais. Está ligada a essa história, a história da instituição que desenvolveu e reificou uma narrativa em que figuram os papéis tradicionais de gênero, atribuindo a homens e mulheres objetos materiais, comportamentos sociais e hábitos culturais específicos de acordo com as identidades presumidas como naturais.

Por essa razão, ao longo do último século, ainda que mulheres $e$ homens homossexuais ocupassem os espaços profissionais nos museus, as representações construídas se mantinham baseadas nos estereótipos tradicionais do masculino e feminino, e qualquer tipo de perspectiva queer sobre o patrimônio era suprimida das narrativas museais.

$\mathrm{O}$ presente repete, tristemente, o passado, quando os museus são levados a fechar portas e janelas ao ousarem fazer da 
diferença um objeto a ser discutido, e se tornam, eles mesmos, sujeitos de críticas movidas pela intolerância. Uma museologia que se pensa queer se faz necessária para que as mulheres, os homens, trans e cis, homo ou heterossexuais, tenham lugar no museu do porvir e possam se colocar novas perguntas sobre o seu passado $e$ o seu futuro.

\section{Referências bibliográficas}

AUDEBERT, Ana. Museologia, gênero e feminismos: sobre mulheres, coleções e museus. Anais do XXIV Encontro Anual do ICOFOM LAM. Musealidade e patrimônio na teoria museológica latino-americana $e$ do Caribe. ICOFOM LAM - Subcomitê Regional do ICOFOM para a América Latina e o Caribe, Ouro Preto - MG, 2016. pp.231-265.

BouniA, Alexandra. Gender and material culture: review article. Museum \& Society, vol. 10, n. 1, 2012, pp.60-65.

BRASIL. Coleção das leis da República dos Estados Unidos do Brasil de 1922. v. 3. Rio de Janeiro, Imprensa Nacional, 1923, pp.72-74; pp.82-85.

BuTLER, Judith. Gender trouble. Feminism and the subversion of identity. New York; London, Routledge, 2007 [1990].

CHARTIER, Roger. Diferenças entre os sexos e a dominação simbólica (nota crítica). cadernos pagu (4), Campinas-SP, Núcleo de Estudos de Gênero-Pagu, 1995, pp.37-47.

CHOAY, Françoise. A alegoria do patrimônio. São Paulo, Estação Liberdade; Editora UNESP, 2001.

CONCURSO para cargos iniciais da carreira de conservador. Revista do Serviço Público, Rio de Janeiro, ano 2, vol. 3, n 1-2, jul./ago. 1939, pp.106-108.

CRENSHAW, Kimberle. Mapping the margins: intersectionality, identity politics, and violence against women of color. Stanford Law Review, vol. 43, n6, 1991, pp.1241-1299.

CUSHMAN, Karen. Museum Studies: The Beginnings, 1900-1926. Museum Studies Journal, Spring, 1984, pp.8-18. 
ELIAS, Norbert. O processo civilizador. vol. 1: Uma breve história dos costumes. Rio de Janeiro, Zahar, 1994.

LAEMMERT, Regina Liberalli. Conservação e restauração de pinturas. Anuário do Museu Nacional de Belas Artes, n 3, Rio de Janeiro, 1941, pp.159-192.

Levin, Amy K. (ed.). Gender, Sexuality and Museums: A Routledge Reader. London, Routledge, 2010.

LEVY, Fortunée. As mulheres e as armas. Anais do Museu Histórico Nacional, vol. IV, 1943, pp.499-520.

LOPES, Maria Margaret. Proeminência na mídia, reputação em ciências: a construção de uma feminista paradigmática e cientista normal no Museu Nacional do Rio de Janeiro. História, Ciências, Saúde Manguinhos, v.15, supl., Rio de Janeiro, jun. 2008, pp.73-95.

MAIRESSE, François. La Notation de Public. In: Annual Conference of The International Committee For Museology/ICOFOM (27), Calgary, Canada, 2005. Symposium Museology and Audience - Museología y El Público de Museos, Munich, ICOM, International Committee for Museology/ICOFOM; ISS: ICOFOM STUDY SERIES, Munich, Germany, n 35, 2005, pp.7-25.

PERROT, Michèle et alii. Culture et pouvoir des femmes: essai d'historiographie. Annales Économies, Sociétés, Civilisations, 41 année, nº 2, 1986, pp.271-293.

POLLAK, M. Memória, esquecimento e silêncio. Estudos Históricos, vol. 2, $n^{\circ} 3$, CPDOC, 1989, pp.3-15.

POMIAN, Krzysztof. Coleção. Enciclopédia Einaudi, vol. 1. MemóriaHistória. Porto, Imprensa Nacional / Casa da Moeda, 1984. pp.51-86.

REAL, Regina Monteiro. Que é técnica de museu? Estudos Brasileiros, Rio de Janeiro, ano 03, vol. 06, nos 16 e 17, jan.-fev./mar.-abr. 1941, pp.109-132.

RECHENA, Aida. Museologia (d)e Género. In: ASENSIO et alii (eds.) SIAM. Séries Iberoamericanas de Museología, vol. 4, 2012, pp.259-269. [http://www.uam.es/mikel.asensio - acesso em 09 out. 2017]. 
SÁ, Ivan Coelho de. História e memória do curso de Museologia: do MHN à Unirio. Anais do Museu Histórico Nacional, vol. 39, Rio de Janeiro, 2007, pp.10-42.

SCHWARZER, Marjorie. Women in the temple: gender and leadership in museums. In: Levin, Amy K. (ed.). Gender, Sexuality and Museums: A Routledge Reader. London, Routledge, 2010, pp.16-27.

SCOTT, Joan. Gênero: uma categoria útil para análise histórica. Revista Educação e Realidade, vol. 20, n 2, Porto Alegre, jul./dez. 1995, pp.71-99.

. História das mulheres. In: BuRKE, Peter (org.). A escrita da história. Novas perspectivas. São Paulo, Unesp, 1992, pp.65-98.

SOIHET, Rachel; PEDRO, Joana M. A emergência da pesquisa na História das Mulheres e das Relações de gênero. Revista Brasileira de História no 54, vol. 27, São Paulo, ANPUH, jul.-dez, 2007, pp.281-300.

SOIHET, Rachel. Violência simbólica: saberes masculinos e representações femininas. Revista Estudos Feministas, vol.5, n 1, Rio de Janeiro, UFRJ/IPHICS, 1997, pp.7-29.

STAROBINSKI, Jean. As máscaras da civilização. Ensaios. São Paulo, Companhia das Letras, 2001. 